\title{
2 On the Politics of Face Masks: A Danish Example
}

Inadmissible information is often information that has something to do with biology (illness, sex, reproduction) or money (poverty) or violence (how money and bodies meet). Inadmissible information might also have to do with being defanged by power (courts, bosses, fathers, editors, and other authorities) or behaving against power in such a way that one soon will be defanged (crime) ${ }^{66}$

I made curtains for my son out of a colorful fabric to block out the morning sun from his bedroom. It was late May 2020. I was sitting outside our house in the afternoon sun, sewing, feeling as if I was taking part in a scene that belonged to a different century. I also made a face mask for my daughter. Beams of sunlight reflected off the needle as it pierced the fabric's teddy bear and pink flower motifs. She is three years old. Everything has to be pink. She asks if she will have to wear the mask when she is finally able to visit her self-isolating grandparents again. When I try on the mask, my glasses fog up, and it leaves me with an unflattering choice between a foggy (glasses on) or blurry (glasses off) view of the world. (HS)

The German cultural theorist Bernhard Siegert has proposed the concept of cultural technique to replace the classical understanding of media. The concept of cultural technique understands media in terms of the relational and ontological properties of things. It sees objects and things such as grids, filters, and doors as media in terms of what they do with us, not what they process or how. This notion of cultural technique emphasizes the ontological status of such objects as in-betweens - as media in the concrete sense, where ontological distinctions are dissolved and replaced by understandings of relationships, processes, effects, and dependencies. ${ }^{67}$

Fabric can be seen as a cultural technique in times of corona. It is used to protect, reassure, curate, shield, separate, and create distance, notably in the form of face masks and other protective clothing, as well as in curtains, and in the marquees used for testing or as extensions of hospital and care facilities. We can interpret these structures and their media representations in light of their global ubiquity and similarity, whereby they become concrete markers of the pandemic by bringing it into visibility. But they are contested symbols, as evinced by the deep divisions around face masks in the US, for example, or the hesitant adoption of face masks in several Western European countries. ${ }^{68}$ As the pandemic has worn on, positions have polarized amid abundant conspiracy 


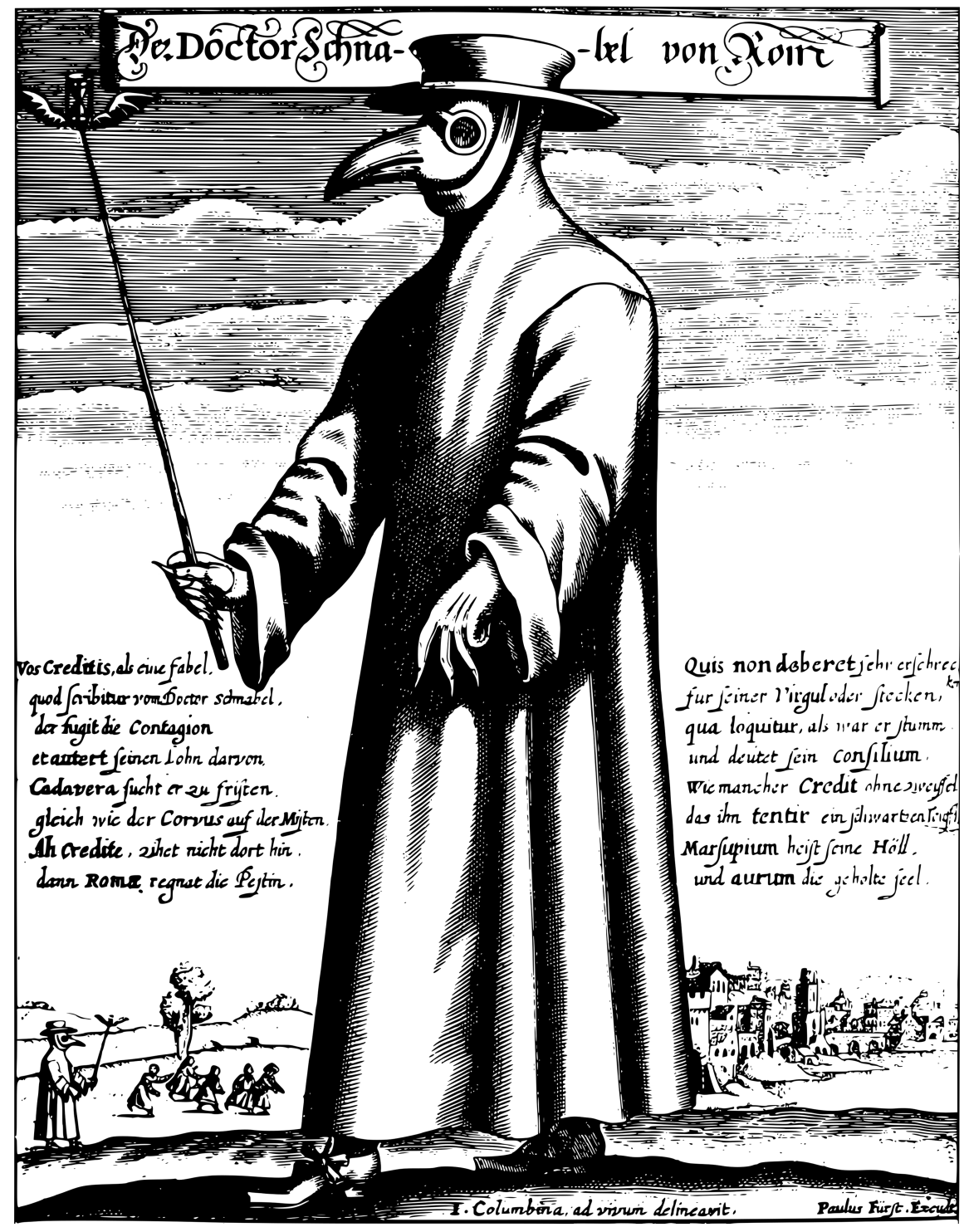

Figure 8: Copper engraving by Paulus Fürst, after a tablet from 1656 by J. Columbina. During the plague, doctors tried to distance themselves from physical interactions with their patients. This image shows the plague doctor Doktor Schnabel. The long beak contained herbs to filter polluted air, which was believed to be the medium of contagion. Image Credit: Enrique Meseguer / Pixabay 
theories: face masks are sometimes seen as a sign of complacency, of citizens being sheep that fail to question their government's authority to impose restrictions, institute rules to prevent contamination, or recommend vaccines. ${ }^{69}$ Yet if we take a step back from the immediate context of COVID-19, we can see the pandemic's fabric architectures and clothing as part of a long history of medical architectures that separate patients with contagious diseases from other groups in society - a history that goes back to ancient times. Just think of the notorious plague doctors of early modernity, who wore beak-like masks, or the many purpose-built and quickly erected pandemic hospitals, e.g. during cholera outbreaks or the 1918-1920 flu pandemic.

Nonetheless, the face mask is about more than just function or protection; it provokes conflicting interpretations. In Denmark in 2020, public health authorities and the general public underwent a general change of heart in their attitude to face masks - from panic over a lack of resources, to dismissal, to a gradual embrace of face masks in light of the late summer's sudden increase in infection numbers. This chapter tells the story of that change of heart, as an example of what the changing politics of pandemic architectures and accessories can tell us about how political responses to the pandemic, and people's reactions to them, are highly situated and dependent on specific relationships and understandings. Relationships and understandings that are highly politicized involve measures that discipline individuals but are experienced affectively. In this way, the touch of a mask's fabric on the skin offers a vehicle to explore different dimensions of touching and being touched both physically and affectively. The chapter unfolds from the onset of the pandemic in Denmark in late February 2020 up until mid-August of that year, when face masks were made mandatory on public transit nationwide for the first time - a watershed moment in the national acceptance of face masks, which later also became mandatory in shops, supermarkets, public institutions, etc.

As media, fabric objects and architectures, such as face masks and COVID19 testing marquees, are coded in particular ways as they perform roles for, with, and toward humans, as well as in relation to viral pathogens. This means that they act as affective markers that negotiate the emotional makeup of the pandemic, making it visible, coding and changing how bodies move and perform in spaces such as health centers, public transit, or open spaces. Fabric - a relatively lightweight material, even in its heavily coated variants - is readily accessible and can be shaped into many types of objects at many scales. Its weave can prevent or facilitate the mediated penetration of light, air, or viral particles, for example. The production of fabric-based objects can be 


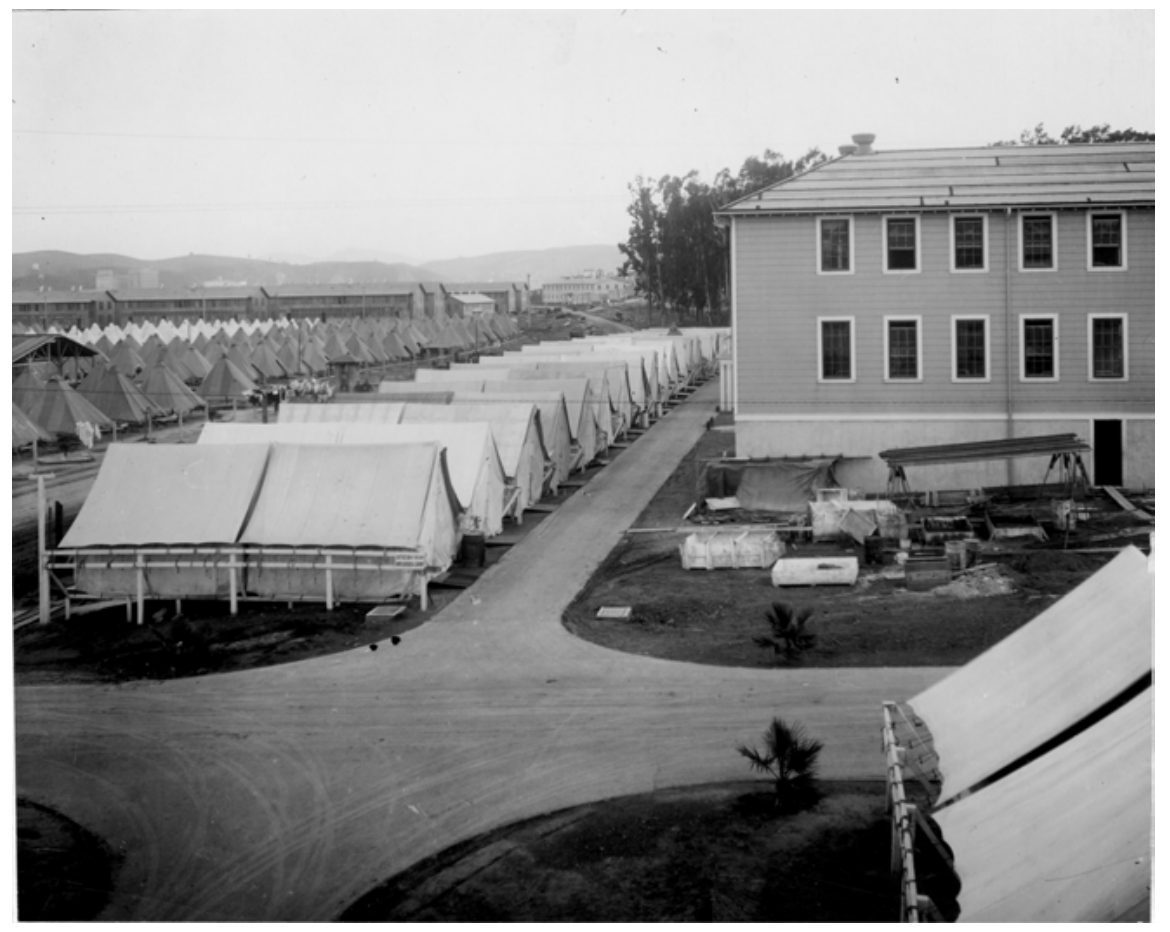

Figure 9: US naval hospital: a general view of inner buildings and influenza emergency camps. Mare Island, California, October 12, 1918. Image Credit: Navy Medicine from Washington, DC, US / Wikimedia Commons 
industrialized and mechanized, or it can require highly specialized skills, or simple forms of craft that are available to anyone with a needle and thread. In any case, fabric-based objects act on and with spatial structures in relation to different scales of intimacy. Just think of the way the mask touches the skin of the face, impacts breathing, and involves particular routines of applying, removing, discarding, washing, or airing the mask itself. Or think of the way fabric is used to demarcate spaces of separation, or to create new purpose-built pandemic architectures for treatment or testing where potential illness is forcedly separated off in tent-like structures. Those structures have become a looming, iconic presence in cities and parking lots, around hospitals and health centers, and in new, intensified border control situations that may also involve COVID19 testing. Hastily erected marquees or temporary treatment centers - just like the emergency treatment facilities seen in images from the Spanish flu pandemic - insist on the urgency as well as the fleeting nature of the crisis, exuding a cruel optimism akin to the tent infrastructures of refugees' or emergency workers' camps, ${ }^{70}$ and with the same political investment in marking dominance or authority through seemingly neutral, white, compound-like structures. ${ }^{71}$ Thus, fabric as a medium in the time of corona raises questions about the virus's economic, affective, political, and ecological implications, as well as about how the pathogen gains an inverse visibility in media and cities, touching and directing people and bodies.

July 26, 2020 saw the first media reports of a shift in Danish public health recommendations about face masks, ${ }^{72}$ which had hitherto been ruled out. From having been a practically nonexistent pandemic accessory in the country, on July 31 face masks were recommended as a "good idea" on rush hour public transit. ${ }^{73}$ Then, on August 15, face masks were made mandatory for all public transit users and personnel.

During the early days of the pandemic, face masks had become a symbol of resourcing problems at hospitals, health clinics, and care homes. For the first six months, however, the Danish authorities insisted that wearing masks in public was not an effective measure. The health authority stated that although masks had some documented effect in laboratory settings, there was insufficient evidence that they would reduce the spread of the disease in public spaces, meaning that there was no basis on which to recommend them; indeed, the authorities even seemed to warn against face masks. ${ }^{74}$ During the early phase of 


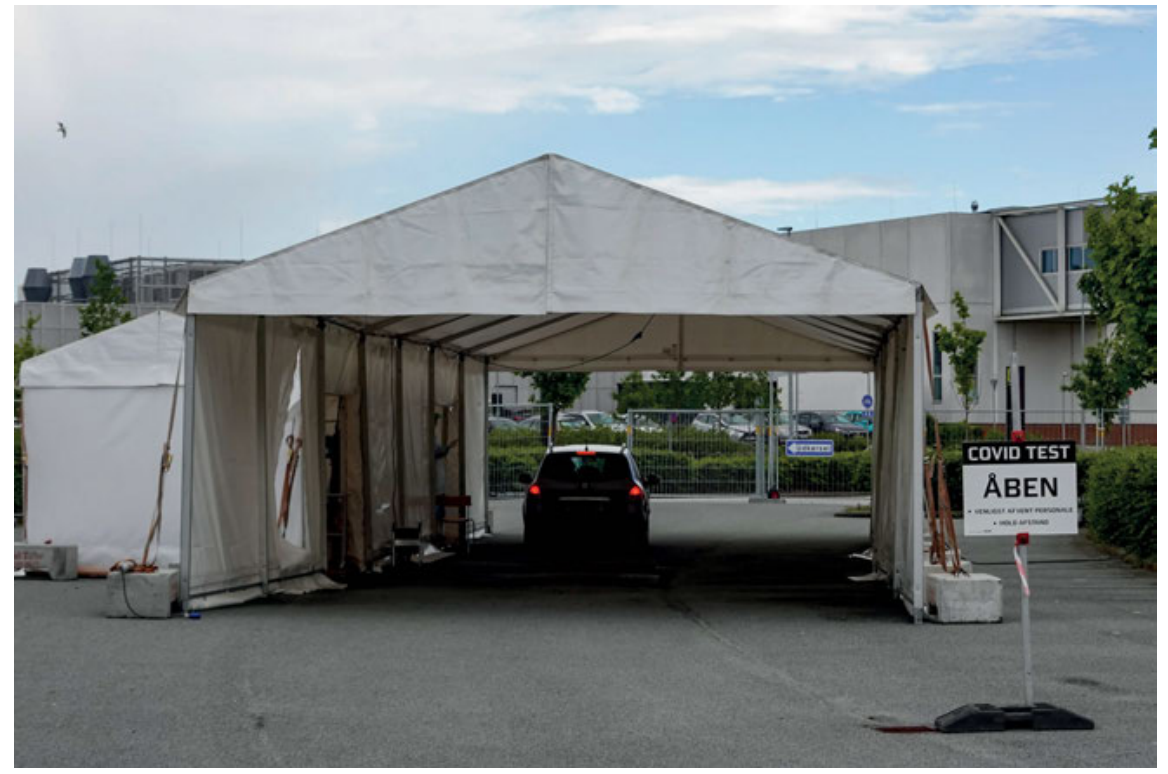

Figure 10: A COVID-19 testing facility and drive-through on the grounds of Skejby Hospital. Aarhus, Denmark, June 8, 2020. Image Credit: Alexanderstock23 / Shutterstock.com 
the pandemic, a two-meter distance rule was in place, everyone was advised to use a handkerchief or sleeve if they had to cough or sneeze, and people with symptoms were advised to stay at home. It was argued that face masks would be an unnecessary addition, and that they might be counterproductive. ${ }^{75}$ In an article dated May 31, 2020, Henning Bundgaard, a scientist, professor, and consultant at Copenhagen University Hospital, emphasized that laboratory studies only gave so much information about everyday life - a comment one might have expected to hear from a humanities scholar rather than a medical doctor. When it came to face masks in public spaces, even this scientist felt compelled to consider the "soft facts" of cultural rhythms and contingencies. He stated that a person wearing a face mask might feel more protected and therefore move closer to other people, or even remove the mask while drinking coffee with a friend (fair enough, one might say, if a meeting involves consuming food or drink), and that such behavior would open a host of possibilities for people to make mistakes, and to disregard other behavioral distance measures introduced to reduce the risk of infection. The slippage he predicted did in fact gradually take place over the summer, although in different ways.

South of the border, in Germany, face masks had been compulsory on public transit since April 22. This meant that people on cross-border trains during the summer of 2020 would put masks on, or take them off, as soon as the train crossed the German-Danish border. In Denmark, where the wearing of masks was noncompulsory, the moral impetus to follow the rules, combined with the uncertainty regarding whether those rules were sensible, was presented as a dissonance between those who wanted to take extra precautions and those who hesitated or even contested the usefulness of face masks. The story developed as a contest between different moral regimes, emphasizing divisions of opinion between those who were considered stubborn by others and those whom others considered overly anxious. ${ }^{76}$

As Denmark's institutions and public life gradually returned with the easing of lockdown, the summer's low infection rate was a pocket of near-normality, and a person in a face mask was a surprising reminder of the pandemic. There was a sense that people wearing masks in public spaces were either members of a risk group or carriers of the disease. ${ }^{77}$ People's appearance in public spaces thus looked very different than media reports from other countries. People returning to Denmark from abroad reported on the experience of wearing masks as something exotic, although some said they had become used to wearing them in 
shops or restaurants at their holiday destinations relatively quickly..$^{78}$ One also wonders whether some of the hesitation in Denmark about introducing certain restrictions, such as social distancing or face masks in restaurants and shops, boiled down to a perception that such measures would impact the positive feelings around production and consumption in an overly negative direction, potentially smothering typical shopping or spending "experiences" in anxiety and thereby limiting people's willingness to spend money to sustain the economy.

On July 9, the recommendations began to change. Along with the debate around the World Health Organization, which officially changed its recommendation in relation to the growing acceptance that the disease is airborne, ${ }^{79}$ now it was suggested that face masks should be worn in situations where a person with (confirmed or suspected) COVID-19 was unable to self-isolate - for example, while traveling to hospital or a testing site. Then on July 31, with the prospect of a return to everyday rush hour rhythms after the summer vacation, and with the virus's basic reproduction rate on the rise, there came the recommendation that people should wear face masks on crowded public transit, on a voluntary basis. The public health authority maintained at that point that although the evidence was not always in favor of wearing masks, changing social behavior and the decline of compliance with physical distancing measures meant that masks were "a good idea." 80 This "good idea” vacillated between one interpretation of risk that placed its hope in individual freedom and the moral duty to selfisolate and maintain distancing, and another interpretation that soothed collective anxieties by changing people's appearance in public spaces.

In early August, Denmark's infection rate began to rise again, and face masks on public transit were made mandatory in areas where smaller outbreaks had occurred. Yet at eleven a.m. on August 15, after months during which the prime minister had given no press briefings on the virus at all, a briefing was broadcast on Danish television: the government announced that face masks would be mandatory on public transit all over the country from the next week onward.

The director of the public health authority, the medical doctor Søren Brostrøm, brought a face mask to this press briefing, sewn out of soft gray fabric. He showed the public how to properly apply and remove the mask, instructing them to carry a plastic bag in which to store the mask while they were not wearing it during the day, and to wash or dispose of it in the evening. Proudly boasting of his twenty years' experience as a medical doctor who had worn face masks on a daily basis, he was able to demonstrate all this correctly, with confidence and elegance. ${ }^{81}$ Brostrøm also suggested that new if not conclusive scientific evidence had now put paid to the previous fear that masks would change 
people's behavior and deter them from complying with distancing and other hygiene measures.

Thus, he withdrew the authorities' previous dismissal of the mask and presented it not just as a good idea, but as a very sensible idea, indeed as a form common sense. As we know, however, the kind of practical judgment needed for an action or form of behavior to be considered commonsensical is precisely the opposite of this: it is self-evident because it grows out of lived experience. In this case, the understanding of what is considered to be self-evident and relevant lived experience changed as the clock struck eleven on a Saturday morning. Moreover, Brostrøm's choice of face mask for the briefing also redeemed fabric masks, which public authorities had previously discounted in favor of surgical masks. ${ }^{82}$ Users of public transit now had a week to stock up on face masks before they became mandatory. The press briefing also floated the possibility that masks might become mandatory in other settings, both public and commercial such as supermarkets or doctors' waiting rooms, in the future - as did indeed happen around two months later.

As the politics of face masks changed, so the practices and meanings of masks also changed. As face masks became more common - made mandatory in certain settings, and used as props in public political spectacles such as press briefings - their semantic valorization slid. Moreover, as this slippage played out, the arguments over it became more complex, raising levels of anxiety and division between different moral formations, as well as instituting new norms regarding how to look and behave in public spaces, and about which measures to prevent the spread of disease were deemed more significant than others. Indeed, the mask came to be a marker of whether you adhered to official advice - a symbol, according to conspiracy theorists, of blind trust in authority. The issue of what constituted "inadmissible information" (to evoke this chapter's epigraph) and what was common sense therefore became attached to questions of power and body politics. ${ }^{83}$

The COVID-19 virus is often described as an intruder that can be fought and conquered in a battle against its errant and erratic workings. ${ }^{84}$ Yet once it has been diffused through our bodies, communities, cities, and countries as a latent presence, we can understand it as a background condition rather than an intruder: a huge, systemic power, like a belief system, or capitalism, or a language. As we learn to "speak corona" through our interactions with the objects, 


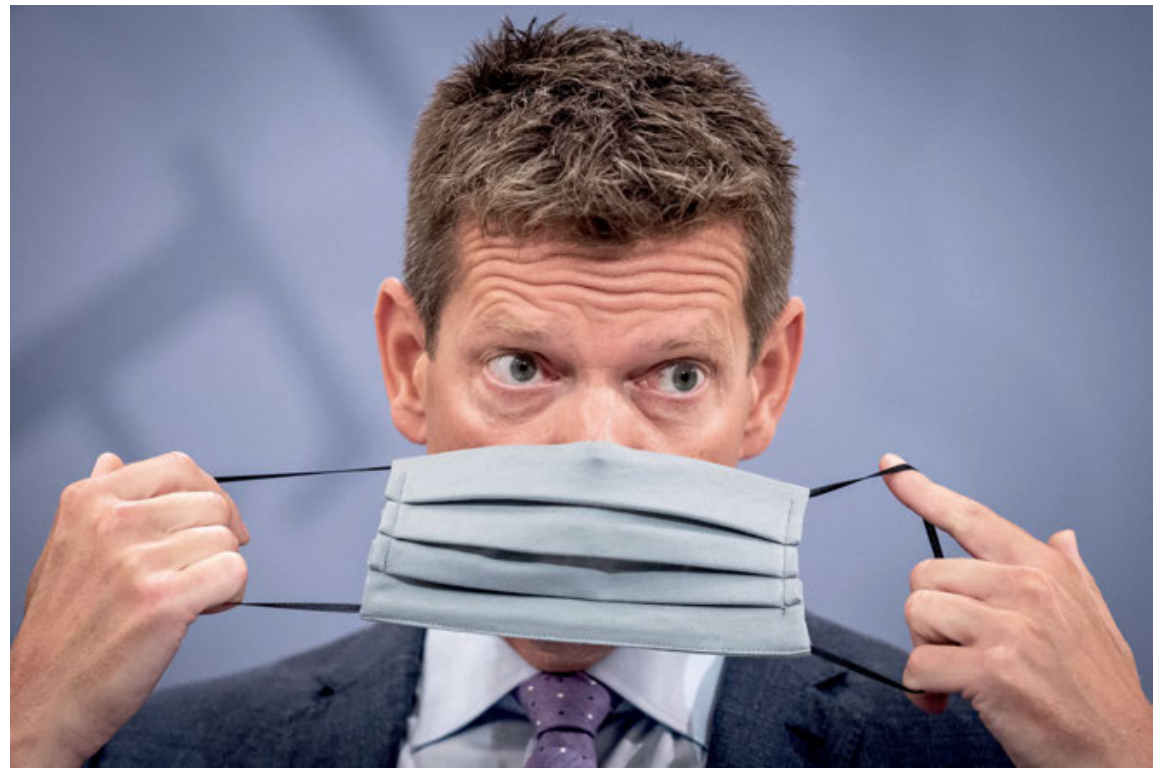

Figure 11: The head of the Danish health authority, Søren Brostrøm, demonstrates how to put on a face mask at a nationally televised press briefing on August 15, 2020. Image Credit: Mads Claus Rasmussen / Ritzau Scanpix 
social rules, and fabrics that serve to shield us from the disease and reduce the risk of infection, this massive institutional transformation also entails a slippage regarding what togetherness and communality in public spaces can mean or look like. Significantly, at a press briefing in February 2021, Søren Brostrøm looked back on all the different measures to which the population had become accustomed over the previous year, referring to his own experience of having to demonstrate how to wear a mask at a press briefing as "transgressive" and even "intimidating." ${ }^{55}$ When people start wearing surgical masks in public spaces, there is a sense of two institutional realms melting together. This mixing of spheres is uncomfortable in a healthy and wealthy Western society such as Denmark, where the sick are treated in sterile hospital settings, and where institutions are built of bricks, mortar, and concrete, rather than plexiglass, fabric, or the duct tape on the supermarket floor that marks out the required distance between shoppers.

Fabric thus plays different roles in pandemic architectures, in servitude to our desire to control the pandemic and its impact. Fabric not only has functional value, but also embodies different cultural operations and symbolic, epistemic, and social processes. The fabric can be close to the skin of the face, an extra layer meant to filter the air and cleanse it of infectious agents. In doing so, the mask covers an expressive part of the face, making communication difficult: it muffles sounds and hides facial expressions, creating a sense of anonymity.

In Western Europe, we mainly know the mask as a medical device. In hospital wards, where a sterile environment is required, we are used to seeing doctors behind an extra layer of protective screens - protected, protecting, and anonymized through surgical uniforms, their covered faces signaling a faceless authority, although this is a less powerful institutional covering of the body than police or military helmets and bulletproof vests. Since the onset of the pandemic, hospital workers' skin has borne red marks left by tightly fitting masks worn on long shifts. ${ }^{86}$ If they are completely covered in protective clothing, hospital staff sometimes wear printed pictures of their own faces on their chests, to give patients a sense of the appearance of the person they are meeting. In a sense, having one's own photo dangling around one's neck like a giant selfie is a humanizing gesture, indicating the human being behind the cloth-covered creature. Yet there is also is something uncanny and even inappropriate about an unflagging prosthetic paper smile, a frozen emoji performing like a severed limb in the midst of sickness and death.

Before the pandemic, few people would willingly walk the city streets with their faces masked. In particular situations in Western societies - such as illegal 


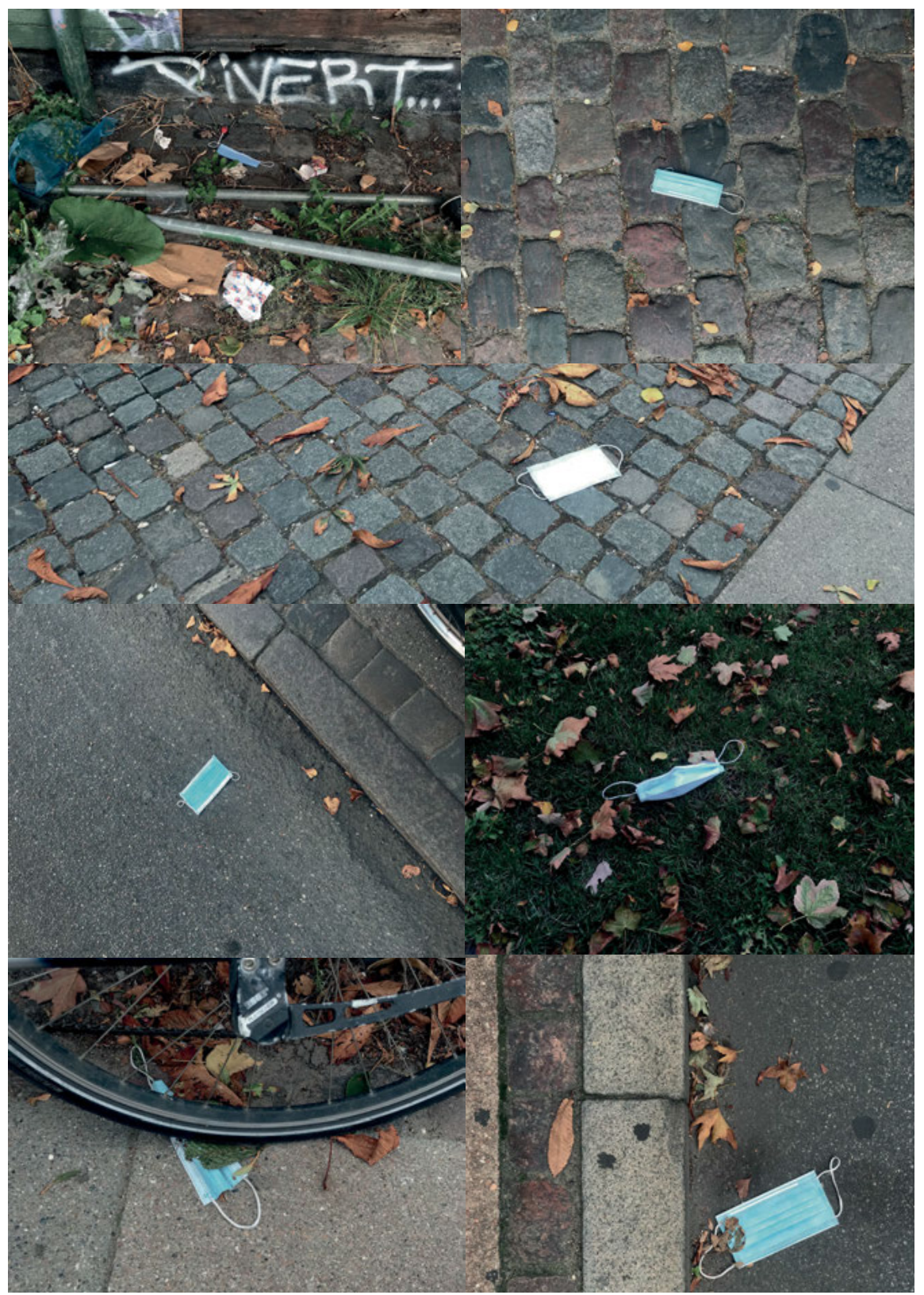

Figure 12: Face masks on the Copenhagen sidewalks. Masks are not only worn but also discarded, becoming pale blue leaves that mix with the autumn colors. Image Credit: Liv Løvetand Rahbek 
demonstrations - the covering of an individual's face is meant to symbolize (controversially) the lack of free speech. The recognizability of facial features is prioritized, tied to prevailing moral patterns infused with individualism. In Denmark, for example, it is a legal requirement that people's faces should be bare on political demonstrations, and there is resistance against religious minorities' use of head or face coverings. ${ }^{87}$ People generally show their faces in public spaces, whether physical or digital, making their features available for scrutiny by other people as well as by facial recognition algorithms.

The face mask operates on a spectrum between safety and reassurance, and in extreme situations between protection and anonymization. The mask is not a neutral agent, and there are different relationships to take up with it. It can be a fashion item, as when the Austrian hosiery producer Wolford and other highend brands charge up to several hundred euros for a single mask..$^{88}$ Masks can also be imprinted with political statements, such as national flags or divisive political slogans. ${ }^{89}$ In softer consumer segments, masks made out of organic cotton, or children's masks with cartoon motifs, complement homemade masks created from carefully chosen pieces of fabric, or improvised masks made out of bandanas, tea towels, or even coffee filters. Moreover, face masks can be used as a humorous gesture. If sown out of washable fabrics such as cotton or silk, the mask suggests a longer lifespan. As with any purchasable product, people can choose a mask to their liking and economic ability. Industrially produced and disposable face masks for use in medicine or the building industry, possibly with various forms of filter, are made from cheap disposable materials, and constitute a new form of visible trash when discarded masks are found on the street. Yet they can still amount to a significant expense for an individual.

As media, face masks are meant to filter the air. Their primary function in public space is to minimize the release of respiratory droplets and aerosols by individuals. People can pass on the disease before they show symptoms. Moreover, a proportion of people infected with COVID-19 show few or no symptoms, and hence can be infected without knowing it; but they can still spread the disease through droplets and aerosols by sneezing, coughing, speaking, singing, or even just breathing into the air. Needless to say, human beings share the air, which is needed to sustain life and enable audible communication. Air is the medium that needs to be purified by a fabric that touches the skin, covering the 

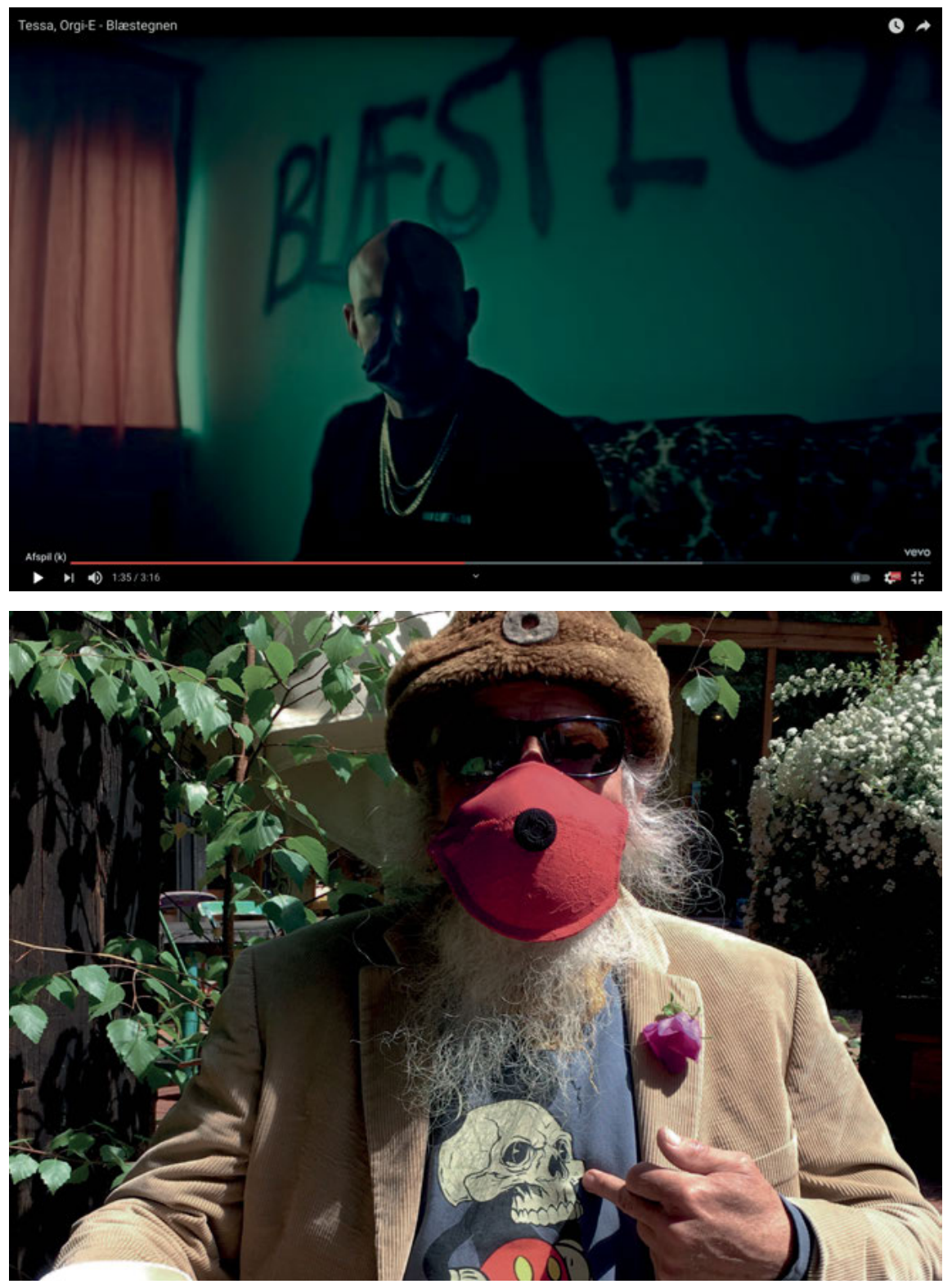

Figure 13: Male artists challenge the use of masks, for example by using women's underwear. Danish rapper Orgi-E wearing G-string panties as a mask in his music video "Blæstegnen," and German artist Rolls Rolf Langhans with a face mask made from a lacy bra. Image Credit: Universal Music Denmark / Orgi-E and Tessa, Private Photo / Hubert Bergmann 
nose and mouth. The mask is a medium that dutifully performs this task, as far as its fit and its density of woven threads allow. It is a cultural technique.

Yet the way masks are used and interpreted in the spaces of the pandemic is steeped in politics, economics, and emotions. Do we cover up to protect others? Do we retreat behind the mask and hinder expressive communication? Do we wish to avoid masks? Do we consider them a serious invasion of our private space, a source of claustrophobia, or just an itchy inconvenience? Do we use them as a personal or political statement? The mask can be worn out of courtesy to the common realm, to those who share the air with us when we are close to one another and can knowingly or unknowingly spread infectious pathogens. At the same time, it is a disciplinary measure, a way to massage the body politics of the living, to avoid future harms from a potentially disabling and deadly disease, and to prevent overstrain on the medical system.

In this context, the mask performs a particular task in relation to those who may be ill but do not feel ill. The moral impetus of the mask is attached to reading one's own body for signs of illness emitted by the nervous system that point to COVID-19: cough, headache, muscular pain, loss of the sense of smell or taste, etc. These symptoms can be hard to distinguish from non-COVID-19related conditions, or they can be absent altogether. Moreover, some people may ignore the symptoms for a variety of reasons, including economic ones. Yet for masks to be as effective as possible, everyone who might be an unknowing transmitter of the disease would have to wear one. This is a dialectical relationship to the unknown that produces uncomfortable feelings: what are the signs of whether someone is willing or able to listen to their body's signals? Moreover, that anxiety can be projected onto oneself or onto others as potentially contagious bodies, complicating the politics of face masks with complex and highly individual affective relationships.

The ethical problem of the mask is therefore also an affective one - whether one can feel symptoms, and whether one acts upon one's feelings - and potentially an economic one: whether one can afford to feel and act upon one's feelings, and what the effects on others will be if one feels and interprets the symptoms appropriately, or if one ignores or is unaware of them, or simply experiences no symptoms to which to react. Moreover, the formal problem of the mask is also a political one that can be enforced through direct power, or nudged, or disregarded in order to avoid the uncomfortable feelings that the mask may mediate in some contexts. The face mask can be promoted as a safety technology, like the seatbelt in a car. Or it can be ridiculed, for example when the Danish rapper Orgi-E - in a music video that includes former Danish prime minister Helle Thorning-Schmidt - wears women's panties as a mock face mask. 
However, the face mask can also be a sign of neoliberal self-management when one ventures into places with the goal of consuming goods or experiences where physical distance is difficult to maintain, such as in shops, restaurants, or airplanes. It can be part of an established institution, such as the necessary separation between health professional and patient: most people remember the frustration and desperation evoked by reports that supplies were running low, when doctors or nurses described the moral choices they had to make, unable as they were to adequately protect themselves and their patients from breathing the same potentially contaminated air. Or it can be thought of as commonsensical, thus speaking to the sensus communis concerning our orientation, sensitivity, and care toward other people as they make up greater collectives. Yet, when the face mask is everywhere, not wearing it is suddenly a dramatic act with political undertones.

Despite this range of interpretations of the face mask as a cultural technique, in the complicated and highly contextual discourses about face masks as a quasi-universal pandemic fabric architecture, there is an orientation toward the greater collective. While this orientation does not necessarily involve the social body of other people, it is nonetheless material in the sense that air is the medium that physically binds us together. Insofar as the air we breathe can be polluted, we can potentially touch the virus through the air. The mask can prevent that touch in a two-way movement, in a situation where any sneeze's nearly invisible substance has a potentially harmful effect, a microscopic touch of disease in times of corona. Moreover, with a mask, the air we breathe is also our own breath - which can be seen through a dialectics of purity and impurity, as a closed system - while the face mask itself can be covered with pathogens and should therefore not be touched.

The face mask raises context-specific political and moral problems that depend on our understanding of the kind of world we in fact share: a world where profit can be made from producing and selling masks as fashion statements or disposable objects, as signs of caring unaccompanied by hard evidence of the extent to which any given face mask actually does the job of cleaning the air. Amid the wild idea of scale evoked when countries invest in disposable masks for wide swaths of the population,,$^{90}$ or when hospitals buy large numbers of masks for their staff - or are unable to do so, given depleted supplies - a simple, low-tech stitched object is bestowed with power to mark the difference between sickness and health, life and death. COVID-19's social effects are played out in conditions that are marked not only by the unequal allocation of suffering in relation to class, age, ability, health, race, gender, and occupation, 
but also by the capitalist logics of profit and distribution, and these effects are tied to particular cultural techniques.

Moving away from the skin, and onto a slightly larger scale, as a cultural technique fabric can be used to visually shield and demarcate. It is used as the main building material in the architecture of COVID-19 test centers, quickly erected emergency hospitals, and wards or corridors for the sick. Fabric is lightweight and can be a canvas for the most fragile and precious cultural expressions. It can be a way of separating the body from the world, creating borders. In the way they are woven, cut, and sewn, fabrics embody ancient cultural history, representing craft and care. But fabric also tells the story of some of the most disrespectful, polluting, and exploitative practices of Western culture: cotton fabric's deep roots in slavery, the plantationocene, and the human and ecological damage this culture created in its wake and with synthetic materials' carbonintensive imprint.

Testing for coronavirus often takes place in breezy, outdoor conditions, sometimes in cars, and often within fabric architectures as shelter from rain or wind. The air that can carry pathogen-bearing droplets and aerosols can also disperse them so that they lose their infectious potential for humans. Despite the high infection rates, many people still do not know on a firsthand basis what it is like to have COVID-19; yet most people know about architectures such as face masks or testing sites, and have had concrete encounters with them. In Western contexts, where institutions like to construct buildings out of bricks or concrete, these often white marquees look like optimistically clean temporary structures. Yet as the high COVID-19 infection rates continue, we may wonder how long these fabric architectures will have to remain in place. In Denmark, which currently offers COVID-19 testing as a completely open and free service as a public good, a vast and very costly public infrastructure has quickly been put into place, augmented with the digital infrastructure of the "corona passport" under proposed legislation for the country's reopening (presented on March 22, 2021). ${ }^{91}$ But will these architectures have to remain in place for so long that they will lose their white, crisp newness, diverting our thoughts rather toward the derelict tents in refugee camps that can become home to large groups of people for years or even decades? Will the marquees soon be disassembled and disappear from view, leaving no trace for the archeologists of the future who will research the COVID-19 pandemic? Or will they remain in place and deteriorate, perhaps changing their function, or waiting on hold for future outbreaks of 
infectious disease, the process of their ruination a constant reminder of the period we are now living through?

At the time of writing, face masks remain a contested but an accepted precaution in Denmark, as in most of the world. But the story of masks' political slide in Denmark shows that they play a significant role in the pandemic's political architectures, on many levels. Although mask wearing is particular and individual, and comes with moral discourses of choice, visibility, and risk management, it is also always intrinsically socially invested. Face masks - as one of several technologies and cultural techniques, alongside hand sanitizers, tracing apps, test kits, etc. - are touted as a way for individuals to contribute to collective health in the pandemic, yet they imply difficult moral and ethical questions about how the individual can transmit and circulate the disease through simple life-sustaining acts such as breathing or speaking. At the same time, they are part of the Western economy's normal production chains, pointing to the polluted world around us. They emphasize that human bodies hover on a threshold as both liminal objects and collective bodies. In doing so, they call attention to issues of purity and danger, harking back to fundamental anthropological questions about how different cultures organize themselves around life and death, with the human body's embeddedness within cultural and natural conditions at their very center. ${ }^{92}$ Wider ecological and social inequalities and exploitative conditions are as imprinted on the fabrics themselves as they are on the resource problems that go along with them. When the fabric of the face mask is brought close to the body, it emphasizes that body as an object of desire for the virus; yet the virus is only one of many agents that connect that body with its context in different ways. Divisions concerning masks are drawn not just along lines of economics, health, or class, but also between affective responses ranging from anxiousness to steadfastness - and the position one may be willing or able to take in the face of the pandemic.

In this context, the term anxiousness can be better understood if we address it through the thought of nineteenth-century Danish philosopher Søren Kierkegaard. Unlike later psychoanalytic understandings, for Kierkegaard anxiety describes the modern condition as a vacillation between the unrestricted freedom of the individual, and thus of humankind, and the correlative, often anxiety-provoking necessity of making choices. ${ }^{93}$ Conversely, steadfastness characterizes an affective position where the individual refuses to see life-sustaining actions reflected in existentialist concepts. As affective responses, both resem- 
ble moral positions against the "new normal" that the human response to the pandemic instantiates, the sensus communis.

An individual can take up variations of these two positions in different contexts. They help us to understand the pandemic as a problem of context. When laid out on a piece of fabric covering the nose and mouth, that context implies possibilities for communication and togetherness as well as distance: physical entities such as air, particles, and possible infectious agents inscribe narratives of disease onto the fabric, in the intimacy of an age-old technology wrapped around the face.

In a blog post about restoring order and decorum after a period of neglect by gardening and caring for plants and the physical environment, the American poet Anne Boyer writes:

There is no volunteering out of this situation, but there is a dialectical relationship to it and with this, opportunities for resistance. You can at least begin to make a path by which your atrophied senses return to shape. There is a lesson in attempting (carefully) the flourishing of your sensitivity even among the brutality. There is a lesson also in observing the current social construction of yourself with the same productive inquiry in which you observe a passing Tesla or a passing cloud. ${ }^{94}$

A consideration of the fabric architectures of the pandemic, such as masks or testing marquees, can yield pointers regarding what constitutes that dialectical relationship. Examining our relationship to pandemic architectures or accessories as cultural techniques can open up a form of productive inquiry, because it emphasizes our intimacy with them: it reveals the human as exposed and always implicated in a particular social and societal context. Boyer suggests that we take a step back from that construction of the self as tied to prevailing political and economic structures, as claimed by physical settings and the partly connective, partly manipulative texture of digital culture - not detaching ourselves from our affective response, but understanding its ties to the context. That is what we are attempting in this book. Investigating touch and touching in times of corona - in this case, through the touch of fabric on our bodies, and in our cities and communities - can be a way to understand that mediating structure of touch as simultaneously and always already physical, social, solitary, and uncomfortably close to all the economic and social markers that separate us. 
